\title{
Risk Factors for SARS-CoV-2 Infection Among US Healthcare Personnel, May-December 2020
}

Nora Chea, Cedric J. Brown, Taniece Eure, Rebecca Alkis Ramirez, Gregory Blazek, Austin R. Penna, Ruoran Li, Christopher A. Czaja, Helen Johnston, Devra Barter, Betsy Feighner Miller, Kathleen Angell, Kristen E. Marshall, Ashley Fell, Sara Lovett, Sarah Lim, Ruth Lynfield, Sarah Shrum Davis, Erin C. Phipps, Marla Sievers, Ghinwa Dumyati, Cathleen Concannon, Kathryn McCullough, Amy Woods,

Sandhya Seshadri, Christopher Myers, Rebecca Pierce, Valerie L.S. Ocampo, Judith A. Guzman-Cottrill, Gabriela Escutia, Monika Samper, Nicola D. Thompson, Shelley S. Magill, Cheri T. Grigg

To determine risk factors for coronavirus disease (COVID-19) among US healthcare personnel (HCP), we conducted a case-control analysis. We collected data about activities outside the workplace and $\mathrm{CO}$ VID-19 patient care activities from HCP with positive severe acute respiratory syndrome coronavirus 2 (SARS-CoV-2) test results (cases) and from HCP with negative test results (controls) in healthcare facilities in 5 US states. We used conditional logistic regression to calculate adjusted matched odds ratios and 95\% Cls for exposures. Among 345 cases and 622 controls, factors associated with risk were having close contact with persons with COVID-19 outside the workplace, having close contact with COVID-19 patients in the workplace, and assisting COVID-19 patients with activities of daily living. Protecting HCP from COVID-19 may require interventions that reduce their exposures outside the workplace and improve their ability to more safely assist COVID-19 patients with activities of daily living.

Tn the United States, $\approx 37$ million cases of coronaIvirus disease (COVID-19) and $>620,000$ deaths had been reported as of June 30, 2021 (1). Given the critical role of healthcare personnel (HCP) in mitigating the COVID-19 pandemic, protecting them from severe acute respiratory syndrome coronavirus 2

Author affiliations: Centers for Disease Control and Prevention, Atlanta, Georgia, USA (N. Chea, C.J. Brown, T. Eure, R.A. Ramirez, G. Blazek, A.R. Penna, R. Li, K.E. Marshall, N.D. Thompson, S.S. Magill, C.T. Grigg); Chenega Professional \& Technical Services, LLC, Chesapeake, Virginia, USA (C.J. Brown, T. Eure); Chenega Enterprise Systems \& Solutions, LLC, Chesapeake (G. Blazek); Colorado Department of Public Health and Environment, Denver, Colorado, USA (C.A. Czaja, H. Johnston, D. Barter, B.F. Miller, K. Angell, K.E. Marshall); Minnesota Department of
(SARS-CoV-2) infection has been a focus of national and international response efforts. However, data on COVID-19 patient care activities that increase risk for SARS-CoV-2 infections among US HCP are limited. To describe factors associated with SARS-CoV-2 infection among US HCP, the Centers for Disease Control and Prevention (CDC) collaborated with Emerging Infections Program (EIP) site staff (2) to conduct a case-control analysis among HCP working in selected healthcare facilities. We assessed associations between SARS-CoV-2 infection in HCP and a variety of potential exposures: having close contact with persons with COVID-19 outside the workplace, having close contact with COVID-19 patients in the workplace, performing COVID-19 patient care activities including aerosol-generating procedures, and using recommended personal protective equipment (PPE) during those activities.

\section{Methods}

\section{Healthcare Facilities and Personnel}

Staff at EIP sites in 5 states (Colorado, Minnesota, New Mexico, New York, and Oregon) recruited a convenience sample of healthcare facilities and

Health, St. Paul, Minnesota, USA (A. Fell, S. Lovett, S. Lim, R. Lynfield); University of New Mexico, Albuquerque, New Mexico, USA (S.S. Davis, E.C. Phipps); New Mexico Department of Health, Santa Fe, New Mexico, USA (M. Sievers); University of Rochester Medical Center, Rochester, New York, USA (G. Dumyati, C. Concannon, K. McCullough, A. Woods, S. Seshadri, C. Myers); Oregon Health Authority, Portland, Oregon, USA (R. Pierce, V.L.S. Ocampo, J.A. Guzman-Cottrill, G. Escutia, M. Samper)

DOI: https://doi.org/10.3201/eid2801.211803 
health systems to participate in the study. Eligible facilities included acute-care hospitals, nursing homes, or other healthcare facilities (e.g., outpatient clinics, urgent care clinics, or free-standing emergency departments). Healthcare personnel were defined as persons serving in healthcare settings with the potential for direct or indirect exposure to patients or infectious materials including body substances (e.g., blood, tissue, and specific body fluids); contaminated medical supplies, devices, and equipment; contaminated environmental surfaces; and contaminated air (3). This activity was reviewed by CDC and was conducted in compliance with applicable federal law and CDC policy (45 C.F.R. part 46.102(1)(2); 21 C.F.R. part 56; 42 U.S.C. \$241(d); 5 U.S.C. \$552a; 44 U.S.C. $\$ 3501$ et seq.). CDC determined that the project was a nonresearch activity and no institutional review board review was required. EIP sites and participating facilities either deemed the project to be a nonresearch activity or obtained institutional review board approval.

\section{Case and Control Definitions and Enrollment}

We defined cases as HCP working in participating healthcare facilities who had a positive SARS-CoV-2 PCR or antigen test (both of which are hereafter referred to as virus test) result from May 19, 2020, through December 6, 2020. To identify cases, EIP site staff obtained weekly lists of HCP with SARS-CoV-2 virus test results from participating healthcare facilities or state or local health departments. EIP site staff attempted to contact all HCP on the weekly lists and enroll all HCP meeting the case definition and agreeing to participate.

We defined controls as HCP who worked in participating healthcare facilities and had a negative SARS-CoV-2 virus test result during the same period used to define cases. To identify controls, EIP site staff randomly selected HCP with negative SARS-CoV-2 virus test results from the weekly lists of HCP test results provided by participating healthcare facilities or state or local health departments. HCP who had previously tested positive for SARS-CoV-2 were not eligible to be included as controls. EIP staff contacted randomly selected HCP and enrolled HCP who met the control definition and agreed to participate.

We matched 2 controls to each case according to the healthcare facility in which the HCP worked and the week of collection of the SARS-CoV-2 virus test; we excluded unmatched cases and controls. To minimize recall bias, we did not enroll HCP if $\geq 60$ days had elapsed since the specimen collection date for the SARS-CoV-2 virus test.

\section{Sample Size Calculation}

The sample size estimate was based on the assumption that $50 \%$ of cases and controls would have had known close contact with COVID-19 patients in the workplace and that $15 \%$ of cases and $5 \%$ of controls would have participated (performed or assisted) in aerosol-generating procedures for COVID-19 patients. With a matched design and twice as many controls as cases, $\approx 200$ cases and 400 controls would be required to detect an odds ratio of 2 as statistically significant with $80 \%$ power.

\section{Data Collection and Exposures of Interest}

From May 28 through December 20, 2020, trained EIP staff conducted telephone interviews of HCP who agreed to participate; they used a standardized questionnaire to collect information about demographics, activities outside the workplace, detailed COVID-19 patient care activities including aerosol-generating procedures, and PPE use during those activities in the 14 days before specimen collection (asymptomatic HCP) or before COVID-19 symptom onset (symptomatic HCP). One case and 7 controls completed a self-administered questionnaire online.

Our primary exposures of interest were having close contact with persons with COVID-19 outside the workplace, having close contact with COVID-19 patients in the workplace, participating in aerosolgenerating procedures for COVID-19 patients, performing selected COVID-19 patient care activities, and wearing recommended PPE during COVID-19 patient care activities. We grouped COVID-19 patient care activities into the following categories: assistance with activities of daily living (ADL; e.g., bathing, eating, toileting) or participating in restraining patients (hereafter, the phrase assisting with ADL also includes participating in restraint); clinical procedures (e.g., phlebotomy, intravenous line insertion, or a surgical procedure); nonprocedure clinical care (e.g., checking vital signs or performing a physical examination); environmental cleaning; respiratory care (e.g., nasal swabbing for SARS-CoV-2 testing, manipulating oxygen or ventilator tubing, or providing tracheostomy care); or administrative activities. Close contact was initially defined as being within $\approx 6$ feet $(\approx 2 \mathrm{~m})$ of a person with SARSCoV-2 infection for at least a few minutes or having unprotected direct contact with infectious secretions or excretions from the patient (3). However, to align with evolving guidance from CDC, we updated the definition of close contact twice during the project period (i.e., to specify a duration of 15 minutes and to include participation in aerosol-generating pro- 
cedures regardless of duration) (4). Recommended PPE for COVID-19 patient care included gloves, gown, N95 respirator or powered air purifying respirator, and face shield or goggles. For this analysis, we considered the following activities to be aerosolgenerating procedures according to CDC guidance: airway suctioning, sputum induction, cardiopulmonary resuscitation, endotracheal intubation or extubation, noninvasive positive pressure ventilation, bronchoscopy, and manual ventilation (5). We also included the following as aerosol-generating procedures because of the lack of data to definitively rule out potential aerosol generation: nebulizer administration, high-flow oxygen delivery, high-frequency oscillatory ventilation, chest physiotherapy, minibronchoalveolar lavage, and breaking the ventilation circuit in a patient receiving invasive mechanical ventilation (6).

Data were collected and managed by using REDCap (Research Electronic Data Capture) $(7,8)$, a secure, web-based software platform designed to support data capture for research studies. It provides an intuitive interface for validated data capture, audit trails for tracking data manipulation and export procedures, automated export procedures for seamless data downloads to common statistical packages, and procedures for data integration and interoperability with external sources.

\section{Statistical Analyses}

We summarized HCP characteristics by using frequencies for categorical variables and medians with interquartile ranges (IQRs) for continuous variables. To determine the variables to include in the multivariable conditional logistic regression models, we used direct acyclic graphs (9). We created 2 separate models to include appropriate HCP for the variables evaluated and calculated adjusted matched odds ratios (amORs) and 95\% CIs for exposure variables.

Model 1 evaluated whether close contact with persons with COVID-19 outside the workplace or close contact with COVID-19 patients in the workplace was associated with SARS-CoV-2 infection in HCP. All cases and matched controls were included in the model, which was adjusted for HCP age, race and ethnicity, healthcare roles, and underlying medical conditions. Model 2 evaluated whether the following selected practices and activities in the workplace were associated with SARS-CoV-2 infection in HCP: participating in aerosol-generating procedures, performing different categories of COVID-19 patient care activities, or wearing rec- ommended PPE during COVID-19 patient care activities. We included in model 2 only HCP who reported close contact with COVID-19 patients in the workplace. In this model, because of the small numbers of cases and controls when matching by week, we postmatched $(10,11)$ by month of SARS-CoV-2 virus test specimen collection and controlled for HCP age, race and ethnicity, healthcare roles, underlying medical conditions, and close contact with persons with COVID-19 outside the workplace. To determine adequate model fit, we assessed Akaike information criteria and the presence of outliers, influential observations, and collinearity. We used SAS version 9.4 statistical software (https://www. sas.com) for the analyses.

\section{Results}

The 25 participating healthcare facilities reported $33,644 \mathrm{HCP}(3,416$ cases and 30,228 controls) to EIP sites. Among 3,416 cases, 1,172 (34.3\%) were interviewed, $1,070(31.3 \%)$ did not respond to contact attempts or declined participation, and 1,174 (34.4\%) were not interviewed because of other reasons (e.g., wrong telephone number or $\geq 60$ days had elapsed since the specimen collection date for the SARSCoV-2 virus test). Of the 1,172 cases who were interviewed, 345 (29.4\%) were included in the casecontrol analysis on the basis of having $\geq 1$ matched control and complete SARS-CoV-2 virus test data. Among 30,228 controls, 2,251 (7.4\%) were selected to be contacted for an interview. Of these 2,251 HCP, $687(30.5 \%)$ were interviewed, 1,174 (52.2\%) did not respond to contact attempts or declined participation, and $390(17.3 \%)$ were not interviewed because of other reasons. Among the 687 controls who were interviewed, 622 (90.5\%) were included on the basis of having 1 matched case and complete SARS-CoV-2 virus test data. The median time from SARS-CoV-2 virus test specimen collection date to interview was 8 days (IQR 6-12) for cases and 16 days (IQR 10-26) for controls.

\section{Characteristics of Cases and Controls}

Among the $967 \mathrm{HCP}, 701$ (72.5\%) reported working in a hospital. Among the 345 cases, median age was 35 (IQR 28-47) years; 268 (77.7\%) were female, 194 (56.2\%) were White non-Hispanic, 96 (27.8\%) were registered nurses, $127(36.8 \%)$ reported close contact with persons with COVID-19 outside the workplace, and $113(32.8 \%)$ reported close contact with COVID-19 patients in the workplace in the 14 days before illness onset or SARS-CoV-2 virus test specimen collection (Appendix Table 1, https://wwwnc.cdc. 
gov/EID/article/28/1/21-1803-App1.pdf). Approximately two thirds of cases and controls reported close contact with family members with COVID-19. Higher percentages of cases than controls identified themselves as being Hispanic or Latino, being $<30$ years of age, being administrative personnel, and having close contact with persons with COVID-19 outside the workplace (Appendix Tables 1-3). Obesity was more frequently reported by cases. The frequency of other underlying medical conditions was similar among cases and controls (Appendix Table 4).
Close Contact with Persons with COVID-19 Outside the Workplace and COVID-19 Patients in the Workplace

According to the model 1 analysis, cases were significantly more likely than controls to report close contact with persons with COVID-19 outside the workplace (amOR 6.2, 95\% CI 4.1-9.4; p<0.001) or close contact with COVID-19 patients in the workplace (amOR 1.6, 95\% CI 1.1-2.3; p = 0.02), after controlling for HCP age, race and ethnicity, healthcare roles, and underlying medical conditions (Table 1).

Table 1. Multivariable conditional logistic regression model to identify characteristics, activities, and practices associated with SARS-

CoV-2 infection among US healthcare personnel (model 1$)^{\star}$

\begin{tabular}{|c|c|c|c|c|}
\hline \multirow[b]{2}{*}{ Characteristic } & \multicolumn{2}{|c|}{ No. (\%) } & \multirow[b]{2}{*}{$\begin{array}{c}\text { amOR } \\
(95 \% \mathrm{Cl}) \dagger\end{array}$} & \multirow[b]{2}{*}{ p value } \\
\hline & $\begin{array}{l}\text { Cases, } \\
\mathrm{n}=345\end{array}$ & $\begin{array}{c}\text { Controls, } \\
n=622\end{array}$ & & \\
\hline \multicolumn{5}{|l|}{ Close contact with persons with COVID-19 outside the workplace } \\
\hline No, unknown, or not reported§ & $218(63.2)$ & $560(90)$ & Referent & \\
\hline Yes & $127(36.8)$ & $62(10.0)$ & $6.2(4.1-9.4)$ & $<0.001$ \\
\hline \multicolumn{5}{|l|}{ Close contact with COVID-19 patients in the workplace $\neq \mathbb{T}$} \\
\hline No, unknown, or not reported & $232(67.2)$ & $398(68.3)$ & Referent & \\
\hline Yes & $113(32.8)$ & $197(31.7)$ & $1.6(1.1-2.3)$ & 0.02 \\
\hline \multicolumn{5}{|l|}{ Age\# } \\
\hline$<30 y$ & $107(31.0)$ & $143(23.0)$ & Referent & \\
\hline$\geq 30 y$ & $238(69.0)$ & $473(76.1)$ & $0.7(0.5-1.0)$ & 0.04 \\
\hline \multicolumn{5}{|l|}{ Any underlying medical condition(s) ${ }^{\star *}$} \\
\hline No & $112(32.5)$ & $222(35.7)$ & Referent & \\
\hline Yes & $233(67.5)$ & $400(64.3)$ & $1.3(0.9-1.8)$ & 0.12 \\
\hline \multicolumn{5}{|l|}{ Race and ethnicity†† } \\
\hline White, non-Hispanic & $194(56.2)$ & $406(65.3)$ & Referent & \\
\hline Hispanic or Latino & $86(24.9)$ & $106(17.0)$ & $1.7(1.1-2.6)$ & 0.02 \\
\hline Black, non-Hispanic & $25(7.2)$ & $28(4.5)$ & $1.7(0.9-3.2)$ & 0.12 \\
\hline Asian, non-Hispanic & $17(4.9)$ & $29(4.7)$ & $1.2(0.6-2.5)$ & 0.56 \\
\hline Other or multiple races, non-Hispanic, or race or ethnicity not reported & $23(6.8)$ & $53(8.5)$ & $0.9(0.5-1.8)$ & 0.81 \\
\hline \multicolumn{5}{|l|}{ Healthcare role } \\
\hline Registered nurse & $96(27.8)$ & $201(32.3)$ & Referent & \\
\hline Administrative personnel & $47(13.6)$ & $50(8.0)$ & $1.8(1.1-3.2)$ & 0.04 \\
\hline Physician & $20(5.8)$ & $63(10.1)$ & $0.9(0.5-1.7)$ & 0.73 \\
\hline Nursing assistant or patient care technician & $24(7.0)$ & $36(5.8)$ & $1.1(0.6-2.2)$ & 0.78 \\
\hline Medical assistant & $16(4.6)$ & $23(3.7)$ & $1.1(0.5-2.5)$ & 0.88 \\
\hline 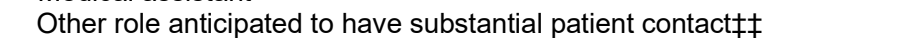 & $58(16.8)$ & $107(17.2)$ & $0.9(0.6-1.5)$ & 0.83 \\
\hline Other role anticipated to have moderate patient contact $\S \S$ & $51(14.8)$ & $77(12.4)$ & $1.1(0.7-1.9)$ & 0.70 \\
\hline Other role anticipated to have minimal patient contactๆள & $24(7.0)$ & $36(5.8)$ & $1.4(0.7-2.7)$ & 0.32 \\
\hline Other role with undefined level of patient contact & $9(2.6)$ & $29(4.7)$ & $0.6(0.2-1.4)$ & 0.25 \\
\hline
\end{tabular}

*amOR, adjusted matched odds ratio; COVID-19, coronavirus disease; IQR, interquartile range; SARS-CoV-2, severe acute respiratory syndrome coronavirus 2.

†Model included 967 healthcare personnel: 345 cases and 622 controls. Among these, there were 71 pairs of 1 case and 1 control, 271 clusters of 1 case and 2 controls, and 3 clusters of 1 case and 3 controls.

fln the $14 \mathrm{~d}$ before illness onset or SARS-CoV-2 virus test specimen collection date.

$\S 15$ cases and 14 controls reported that they did not know if they had close contact with persons with COVID-19 outside the workplace; data were missing for 1 control.

\15 cases and 27 controls reported that they did not know if they had close contact with COVID-19 patients in the workplace; data were missing for 1 control.

\#Age was not reported for 6 controls; these healthcare personnel were grouped as $<30 \mathrm{y}$.

${ }^{* *}$ Asthma, rhinitis, chronic obstructive pulmonary disease or other chronic lung diseases, hypertension or heart conditions, diabetes mellitus, chronic kidney disease or hemodialysis, autoimmune or rheumatologic disease, active cancer, solid organ or hematopoietic stem cell transplant, other immunosuppressing conditions, chronic liver disease, pregnancy, current or recent smoking (i.e., within a year of SARS-CoV-2 virus test specimen collection date), and obesity or severe obesity with body mass index $\geq 30$.

†tRace was not reported for 16 cases and 27 controls; ethnicity was missing for 14 cases and 24 controls.

$\ddagger \ddagger$ Dental healthcare provider, emergency medical services personnel, licensed practical nurse, nurse practitioner, occupational therapist, other nurse, physician assistant, physical therapist or assistant, phlebotomist, respiratory therapist, radiology technician, speech-language pathologist, and surgical, medical, or emergency technician.

$\S \S N o n p h y s i c i a n$ behavioral health provider, chaplain, care coordinator, dietician, environmental services personnel, food services personnel, patient transport personnel, research personnel, social worker, or student.

TTाFacilities maintenance personnel, medical equipment technician, laboratory personnel, or pharmacist. Detailed healthcare roles and area of the facility in which HCP worked are available in Appendix Tables 2 and 3 (https://wwwnc.cdc.gov/EID/article/28/1/21-1803-App1.pdf). 
Table 2. Multivariable conditional logistic regression model to identify activities and practices associated with SARS-CoV-2 infection among US healthcare personnel who reported caring for COVID-19 patients in the workplace (model 2)*

\begin{tabular}{|c|c|c|c|c|}
\hline \multirow[b]{2}{*}{ Characteristic } & \multicolumn{2}{|c|}{ No. $(\%)$} & \multirow[b]{2}{*}{$\begin{array}{c}\text { amOR }(95 \% \\
\text { Cl) } \dagger\end{array}$} & \multirow[b]{2}{*}{ p value } \\
\hline & $\begin{array}{c}\text { Cases, } \mathrm{n}= \\
105\end{array}$ & $\begin{array}{c}\text { Controls, } n \\
=169\end{array}$ & & \\
\hline \multicolumn{5}{|l|}{ Participated in AGP } \\
\hline No, unknown, or missing & $72(68.6)$ & $123(72.8)$ & Referent & \\
\hline Yes & $33(31.4)$ & $47(27.8)$ & $0.9(0.4-2.0)$ & 0.84 \\
\hline \multicolumn{5}{|c|}{ Wore recommended personal protective equipment all the time during non-AGP COVID-19 patient care } \\
\hline No, unknown, or missing & $67(63.8)$ & $110(65.1)$ & Referent & \\
\hline Yes & $38(36.2)$ & $59(34.9)$ & $0.9(0.5-2.0)$ & 0.88 \\
\hline \multicolumn{5}{|l|}{ Assisted COVID-19 patients with activities of daily living } \\
\hline No & $31(29.5)$ & $79(46.8)$ & Referent & \\
\hline Yes & $74(70.5)$ & $90(53.2)$ & $4.7(1.7-12.7)$ & 0.003 \\
\hline \multicolumn{5}{|l|}{ Provided nonprocedure clinical care to COVID-19 patients } \\
\hline No & $19(18.1)$ & $35(20.7)$ & Referent & \\
\hline Yes & $86(81.9)$ & $134(79.3)$ & $0.9(0.3-2.6)$ & 0.88 \\
\hline \multicolumn{5}{|l|}{ Performed procedures on COVID-19 patients } \\
\hline No & $56(53.3)$ & $84(49.7)$ & Referent & \\
\hline Yes & 49 (46.7) & $85(50.3)$ & $0.6(0.3-1.4)$ & 0.25 \\
\hline \multicolumn{5}{|l|}{ Performed environmental cleaning activities in COVID-19 patient care area } \\
\hline No & $53(50.5)$ & $100(59.2)$ & Referent & \\
\hline Yes & $52(49.5)$ & $69(40.8)$ & $1.2(0.5-2.8)$ & 0.69 \\
\hline \multicolumn{5}{|l|}{ Provided respiratory care to COVID-19 patients } \\
\hline No & $51(48.6)$ & $88(52.1)$ & Referent & \\
\hline Yes & $54(51.4)$ & $81(47.9)$ & $0.8(0.3-2.0)$ & 0.70 \\
\hline \multicolumn{5}{|l|}{ Performed administrative activities with COVID-19 patients } \\
\hline No & $94(89.5)$ & $149(88.2)$ & Referent & \\
\hline Yes & $11(10.5)$ & $20(11.8)$ & $0.9(0.3-3.2)$ & 0.90 \\
\hline \multicolumn{5}{|l|}{ Close contact with persons with COVID-19 outside the workplace } \\
\hline No, unknown, or missing & $86(81.9)$ & $160(94.7)$ & Referent & \\
\hline Yes & $19(18.1)$ & $9(5.3)$ & $4.9(1.7-13.9)$ & 0.003 \\
\hline \multicolumn{5}{|l|}{ Healthcare role } \\
\hline Registered nurse & $39(37.1)$ & $69(40.8)$ & Referent & \\
\hline Administrative personnel & $3(2.9)$ & $6(3.6)$ & $2.6(0.3-24.8)$ & 0.40 \\
\hline Nursing assistant or patient care technician & $10(9.5)$ & $16(9.5)$ & $0.4(0.1-1.6)$ & 0.22 \\
\hline Physician & $4(3.8)$ & $23(13.6)$ & $0.6(0.1-3.7)$ & 0.60 \\
\hline Medical assistant & $3(2.9)$ & $4(2.4)$ & $1.7(0.2-12.5)$ & 0.60 \\
\hline Other role anticipated to have substantial patient contact & $36(34.3)$ & $35(20.7)$ & $2.6(1.1-6.5)$ & 0.04 \\
\hline Other role anticipated to have moderate patient contact & $6(5.7)$ & $10(5.9)$ & $1.3(0.2-7.9)$ & 0.75 \\
\hline Other role anticipated to have minimal patient contact & $2(1.9)$ & $2(1.2)$ & $4.1(0.2-78.4)$ & 0.35 \\
\hline Other role with undefined level of patient contact & $2(1.9)$ & $4(2.4)$ & $0.7(0.1-6.6)$ & 0.73 \\
\hline \multicolumn{5}{|l|}{ Race and ethnicity } \\
\hline White, non-Hispanic & $63(60.0)$ & $102(60.4)$ & Referent & \\
\hline Hispanic or Latino & $31(29.5)$ & $34(20.1)$ & $2.1(0.9-4.8)$ & 0.07 \\
\hline Asian, non-Hispanic & $4(3.8)$ & $8(4.7)$ & $0.8(0.2-3.8)$ & 0.83 \\
\hline Black, non-Hispanic & $3(2.9)$ & $6(3.6)$ & $0.7(0.1-4.4)$ & 0.73 \\
\hline Other or multiple races, non-Hispanic or race or ethnicity not reported & $4(3.8)$ & $19(11.2)$ & $0.29(0.1-1.2)$ & 0.09 \\
\hline \multicolumn{5}{|l|}{ Any underlying condition(s) } \\
\hline No & $26(24.8)$ & $62(36.7)$ & Referent & \\
\hline Yes & 79 (75.2) & $107(63.3)$ & $2.5(1.2-5.1)$ & 0.013 \\
\hline \multicolumn{5}{|l|}{ Age, ył } \\
\hline$<30$ & $67(63.8)$ & $127(75.2)$ & Referent & \\
\hline$\geq 30$ & $38(36.2)$ & $42(24.8)$ & $0.5(0.2-0.9)$ & 0.036 \\
\hline $\begin{array}{l}\text { "AGP, aerosol-generating procedures; amOR, adjusted matched odds ratio; CO } \\
\text { †Model included } 274 \mathrm{HCP}(105 \text { cases and } 169 \text { controls). HCP were postmatche } \\
\text { largest cluster with } 10 \text { cases and } 20 \text { controls. } \\
\ddagger \text { Age was not reported for } 3 \text { controls; these HCP were grouped as }<30 \mathrm{y} \text {. }\end{array}$ & ters, each & & 1 contrel & \\
\hline
\end{tabular}

\section{Characteristics of HCP Reporting Close Contact with Patients with COVID-19 in the Workplace}

Among the $310 \mathrm{HCP}$ who reported close contact with COVID-19 patients in the workplace, cases and controls reported performing similar patient care activities, except a higher percentage of cases $(69.9 \%)$ than controls $(54.3 \%)$ reported assisting COVID-19 patients with their ADL (Appendix Table 5). Of the $87(28.4 \%) \mathrm{HCP}$ who participated in aerosol-generating procedures, the proportion of cases and controls who reported wearing all recommended PPE all the time varied by the type of aerosol-generating procedure. Of note, the percentages of cases who reported wearing all recommended PPE all the time during 
common aerosol-generating procedures such as noninvasive positive pressure ventilation, manual ventilation, nebulization administration, or high-flow oxygen delivery were lower than the percentages of controls who reported the same (Appendix Table 5).

\section{COVID-19 Patient Care Activities and PPE Use}

According to the model 2 analysis, 274 (88.4\%) of 310 HCP who reported close contact with COVID-19 patients in the workplace were postmatched. After controlling for HCP age, race and ethnicity, healthcare roles, underlying medical conditions, and close contact with persons with COVID-19 outside the workplace, cases were significantly more likely than controls to report assisting COVID-19 patients with their ADL (amOR 4.7, 95\% CI 1.7-12.7; $p=0.003$ ); however, no differences in aerosol-generating procedure participation (amOR 0.9, 95\% CI 0.4-2.0; $\mathrm{p}=$ 0.84) or wearing recommended PPE all the time during COVID-19 patient care activities (amOR 0.9, 95\% CI 0.5-2.0; $\mathrm{p}=0.88$ ) were identified among cases and controls (Table 2).

\section{Discussion}

Our analysis included 967 US HCP from 21 healthcare facilities in 5 US states and used data from interviews conducted before widespread availability of COVID-19 vaccines. After controlling for demographic characteristics, healthcare roles, and underlying medical conditions, we found that compared with matched controls, odds for cases were 6.2-fold higher for reporting close contact with persons with COVID-19 outside the workplace; 1.6-fold higher for reporting close contact with COVID-19 patients in the workplace; and, among HCP who reported close contact with COVID-19 patients in the workplace, 4.7-fold higher for assisting COVID-19 patients with their ADL.

The greater odds of cases reporting close contact with persons with COVID-19 outside the workplace is consistent with findings of multiple studies, such as studies by Lentz et al., which included $>1,600 \mathrm{HCP}$ from 67 countries, and by Jacob et al., which included $>24,000 \mathrm{HCP}$ from 4 large healthcare systems in 3 US states (12-20). Our analysis also showed that most cases reported close contact with family members with COVID-19. This finding underscores the value of interventions aimed at mitigating community transmission of SARS-CoV-2, particularly among racial and ethnic minority groups that have been disproportionately affected by COVID-19 $(21,22)$.

Some studies have not identified an association between SARS-CoV-2 infection in HCP and close contact with COVID-19 patients in the workplace (13-18). Our analysis, however, showed that assisting COVID-19 patients with ADL was independently associated with being an HCP case. HCP might be less likely to adhere to infection prevention measures during patient care activities that are not perceived to be high risk compared with activities such as aerosol-generating procedures. In addition, during periods of PPE shortages, healthcare facilities may have reserved selected PPE, such as N95 respirators, for HCP in certain roles or those participating in aerosolgenerating procedures, restricting the availability of some protective equipment for use when performing other patient care tasks perceived to be less risky. Continued reinforcement of recommended infection prevention measures in healthcare settings, especially during activities that require prolonged close contact with COVID-19 patients, is needed. Future studies may better describe COVID-19 patient care activities that pose the greatest risk to HCP and are most amenable to interventions.

In a scientific brief dated May 7, 2020, CDC described the 3 modes of SARS-CoV-2 transmission: "1) inhalation of very fine respiratory droplets and aerosol particles, 2) deposition of respiratory droplets and particles on exposed mucous membranes in the mouth, nose, or eye by direct splashes and sprays, and 3) touching mucous membranes with hands that have been soiled either directly by virus-containing respiratory fluids or indirectly by touching surfaces with virus on them" (23). Based on experience with SARS-CoV-1, there have been concerns that risk for infection may be higher for HCP who participate in aerosol-generating procedures than those who do not because of the proximity and time spent with patients and the large quantity of aerosol particles generated during such procedures (24). We did not detect a difference in reported aerosol-generating procedure participation between cases and controls, which is consistent with results reported by Lentz et al. (12). This lack of association may be explained by HCP use of effective infection prevention measures (25-28) implemented since the start of the pandemic, including use of recommended PPE. It should be noted that our analysis included a broader definition of aerosol-generating procedure than CDC and World Health Organization guidance $(27,28)$. Recent studies showed that some aerosol-generating procedures included in public health guidance, such as intubation and extubation, generated negligible amounts of aerosols if performed on asymptomatic patients in controlled settings $(29,30)$. 
Assessing the effect of PPE use on SARS-CoV-2 transmission is challenging, especially when reported use is based on HCP recall rather than observation. HCP may have reported having used recommended PPE all the time even when they had not, knowing that this was the socially desirable response. Such reporting bias might explain why we did not observe a protective effect of wearing recommended PPE all the time for HCP engaged in COVID-19 patient care activities, a finding that has been reported by others (31). Other potential explanations for the lack of association between PPE use and COVID-19 case status among HCP include the small numbers of cases and controls in our analysis, limiting our ability to detect statistically significant differences; HCP participation in multiple patient care activities that may have placed them at risk, including aerosol-generating procedures; and the inability to assess whether PPE was used correctly. Other prevention measures, such as use of source control for patients and performing activities in airborne infection isolation rooms, may have masked the effect of PPE use on transmission of SARS-CoV-2 to HCP (27).

The first limitation of our study is that testing practices and test types may have varied among participating facilities. The exact accuracy of the tests used was unknown and was not accounted for in our analysis. A small number of cases and controls could have been misclassified on the basis of falsepositive or false-negative results. A second limitation is that although the minimum target sample size was achieved, the percentages of HCP who reported close contact with COVID-19 patients in the workplace were lower than those used for the sample size calculation, limiting our ability to detect significant differences in workplace exposures between cases and controls. Third, we included a convenience sample of healthcare facilities at 5 EIP sites, and most participating facilities were acute-care hospitals. In addition, although controls were randomly selected to be contacted for interview, the cases and controls who responded to contact attempts and agreed to participate might not be representative of all US HCP and, therefore, results may not be generalizable to all US HCP. Fourth, differential exposure misclassification may have resulted from the time that elapsed between HCP SARS-CoV-2 virus test specimen collection and the interview. The time from SARS-CoV-2 virus test specimen collection to interview was longer for controls than for cases. In addition, cases may have been more likely than controls to remember close contact with persons with COVID-19, resulting in recall bias. Fifth, our analysis included practices and activities conducted by HCP before COVID-19 vaccines were available and before detection of the Delta variant. Because of evolving infection prevention and control guidance, testing practices, vaccine availability, and SARS-CoV-2 variant emergence, the risk factors identified in this analysis should be interpreted in the context of current guidance and knowledge.

In conclusion, according to data gathered from HCP interviews conducted before widespread availability of COVID-19 vaccines, HCP cases reported more frequent close contact with persons with COVID-19 outside the workplace and COVID-19 patients in the workplace than did HCP controls. These findings suggest that in addition to vaccination and healthcare infection prevention and control measures, protecting HCP requires interventions that reduce HCP exposures to SARS-CoV-2 in their communities. Among HCP who provided care for COVID-19 patients, cases reported more frequently assisting COVID-19 patients with ADL than did controls. Protecting HCP may require interventions that reduce COVID-19 exposures outside the workplace and improve HCP's ability to assist COVID-19 patients with ADL more safely. Infection control training programs and measures specifically focused on protecting HCP may be particularly useful for reducing SARS-CoV-2 transmission in healthcare facilities.

\section{Acknowledgments}

We thank the HCP, healthcare facilities staff, and state and local public health partners who participated in this effort. We also thank Davis Melin, Kylie Yocum, Leah Donovan, Elizabeth Palmi, Jacy Walters, Leslie Lovett, Gerit Wagner, Emilija Motivans, Caroline Habrun, Kristina G Flores, Yadira Salazar-Sanchez, Lezah Brown, Melissa Christian, Marissa Tracy, and Virginia Cafferky for their contributions to this effort.

This project was supported by CDC through a cooperative agreement with the EIP sites. R.P. receives personal fees from the Society for Healthcare Epidemiology of America, J.A.G.-C. received grants from Oregon Health Authority during the conduct of the study, and G.D. received a personal fee from Roche Diagnostic as part of an advisory team.

\section{About the Author}

Dr. Chea is a medical epidemiologist with the Division of Healthcare Quality Promotion, National Center for Emerging and Zoonotic Infectious Diseases, CDC, Atlanta. His primary research interest is healthcare epidemiology, including healthcare-associated infections and antimicrobial resistance. 


\section{References}

1. Centers for Disease Control and Prevention. COVID data tracker weekly review [cited 2021 Jun 30]. https://www.cdc.gov/coronavirus/2019-ncov/covid-data/ covidview/index.html

2. Centers for Disease Control and Prevention. Emerging Infections Program sites [cited 2021 Aug 19]. https://www.cdc.gov/ncezid/dpei/eip/eip-sites.html

3. Centers for Disease Control and Prevention. Coronavirus disease 2019 (COVID-19): interim infection prevention and control recommendations for healthcare personnel during the coronavirus disease 2019 (COVID-19) pandemic [cited 2021 Aug 19]. https:/ / www.cdc.gov/coronavirus/ 2019-ncov/hcp/infection-control-recommendations.html

4. Chea N, Eure T, Penna AR, Brown CJ, Nadle J, Godine D, et al. Practices and activities among healthcare personnel with SARS-CoV-2 infection working in different healthcare settings - 10 Emerging Infections Program sites, AprilNovember 2020. Infect Control Hosp Epidemiol. 2021 Jun 2 [Epub ahead of print].

5. Centers for Disease Control and Prevention. Clinical questions about COVID-19: questions and answers. Which procedures are considered aerosol generating procedures in healthcare settings? [cited 2021 May 17]. https:/ / www.cdc. gov/coronavirus/2019-ncov/hcp/faq.html

6. Tran K, Cimon K, Severn M, Pessoa-Silva CL, Conly J. Aerosol generating procedures and risk of transmission of acute respiratory infections to healthcare workers: a systematic review. PLoS One. 2012;7:e35797. https://doi.org/10.1371/journal.pone.0035797

7. Harris PA, Taylor R, Minor BL, Elliott V, Fernandez M, O'Neal L, et al.; REDCap Consortium. The REDCap Consortium: building an international community of software platform partners. J Biomed Inform. 2019;95:103208. https://doi.org/10.1016/j.jbi.2019.103208

8. Harris PA, Taylor R, Thielke R, Payne J, Gonzalez N, Conde JG. Research electronic data capture (REDCap) - a metadata-driven methodology and workflow process for providing translational research informatics support. J Biomed Inform. 2009;42:377-81. https:/ / doi.org/10.1016/ j.jbi.2008.08.010

9. Textor J. Drawing and analyzing causal DAGs with DAGitty [cited 2021 Jun 30]. http:/ / dagitty.net/manual-3.x.pdf

10. Stürmer $\mathrm{T}$, Brenner $\mathrm{H}$. Flexible matching strategies to increase power and efficiency to detect and estimate gene-environment interactions in case-control studies. Am J Epidemiol. 2002;155:593-602. https://doi.org/10.1093/aje/155.7.593

11. Pearce N. Analysis of matched case-control studies. BMJ. 2016;352:i969. https://doi.org/10.1136/bmj.i969

12. Lentz RJ, Colt H, Chen H, Cordovilla R, Popevic S, Tahura S, et al. Assessing coronavirus disease 2019 (COVID-19) transmission to healthcare personnel: the global ACT-HCP case-control study. Infect Control Hosp Epidemiol. 2020;42:381-7.

13. Jacob JT, Baker JM, Fridkin SK, Lopman BA, Steinberg JP, Christenson RH, et al. Risk factors associated with SARSCoV-2 seropositivity among US health care personnel. JAMA Netw Open. 2021;4:e211283. https:/ / doi.org/10.1001/ jamanetworkopen.2021.1283

14. Baker JM, Nelson KN, Overton E, Lopman BA, Lash TL, Photakis M, et al. Quantification of occupational and community risk factors for SARS-CoV-2 seropositivity among health care workers in a large U.S. health care system. Ann Intern Med. 2021;174:649-54.

15. Braun KM, Moreno GK, Buys A, Somsen ED, Bobholz M, Accola MA, et al. Viral sequencing reveals US healthcare personnel rarely become infected with SARS-CoV-2 through patient contact. Clin Infect Dis. 2021;73:e1329-36. https://doi.org/10.1093/cid/ciab281

16. Rosser JI, Roltgen K, Dymock M, Shepard J, Martin A, Hogan CA, et al. Severe acute respiratory coronavirus virus 2 (SARS-CoV-2) seroprevalence in healthcare personnel in northern California early in the coronavirus disease 2019 (COVID-19) pandemic. Infect Control Hosp Epidemiol. 2021;42:1053-9.

17. Steensels D, Oris E, Coninx L, Nuyens D, Delforge ML, Vermeersch $\mathrm{P}$, et al. Hospital-wide SARS-CoV-2 antibody screening in 3056 staff in a tertiary center in Belgium. JAMA. 2020;324:195-7. https://doi.org/10.1001/jama.2020.11160

18. El Abdellati K, Coppens V, Goossens J, Theeten H, Van Damme P, Berens A, et al. Hospital-wide SARS-CoV-2 antibody screening of staff in a university psychiatric centre in Belgium. BJPsych Open. 2021;7:e40. https:/ / doi.org/ 10.1192/bjo.2020.172

19. Banerjee A, Mukherjee K, Bhattacharjee D, Garai D, Chakraborty R. Status of health-care workers in relation to COVID-19 infection: a retrospective study in a Level 4 COVID hospital in Eastern India. J Assoc Physicians India. 2020;68:55-7.

20. Chico-Sánchez P, Gras-Valentí P, Mora-Muriel JG, Algado-Sellés N, Sánchez-Payá J, Llorens P; Grupo de Trabajo COVID-19 del Servicio de MedicinaPreventiva; Grupo de Trabajo COVID-19 de la Comisión de Infecciones. Impact of the COVID-19 pandemic on health care workers in a tertiary care hospital emergency department. Emergencias. 2020;32:227-32.

21. Smith AR, DeVies J, Caruso E, Radhakrishnan L, Sheppard M, Stein Z, et al. Emergency department visits for COVID-19 by race and ethnicity -13 states, OctoberDecember 2020. MMWR Morb Mortal Wkly Rep. 2021; 70:566-9. https://doi.org/10.15585/mmwr.mm7015e3

22. Van Dyke ME, Mendoza MC, Li W, Parker EM, Belay B, Davis EM, et al. Racial and ethnic disparities in COVID-19 incidence by age, sex, and period among persons aged $<25$ years - 16 U.S. jurisdictions, January 1-December 31, 2020. MMWR Morb Mortal Wkly Rep 2021;70:382-388. https:/ / doi.org/10.15585/mmwr.mm7011e1

23. Centers for Disease Control and Prevention. Scientific brief: SARS-CoV-2 transmission [cited 2021 Jun 30]. https:// www.cdc.gov/coronavirus/2019-ncov/science/ science-briefs/sars-cov-2-transmission.html

24. Chan VW, Ng HH, Rahman L, Tang A, Tang KP, Mok A, et al. Transmission of severe acute respiratory syndrome coronavirus 1 and severe acute respiratory syndrome coronavirus 2 during aerosol-generating procedures in critical care: a systematic review and meta-analysis of observational studies. Crit Care Med. 2021;49:1159-68.

25. Godbout EJ, Pryor R, Harmon M, Montpetit A, Greer J, Bachmann LM, et al. Severe acute respiratory coronavirus virus 2 (SARS-CoV-2) seroprevalence among healthcare workers in a low prevalence region. Infect Control Hosp Epidemiol. 2020 Dec 14 [Epub ahead of print]. https:/ / doi.org/10.1017/ice.2020.1374

26. Hunter BR, Dbeibo L, Weaver CS, Beeler C, Saysana M, Zimmerman MK, et al. Seroprevalence of severe acute respiratory coronavirus virus 2 (SARS-CoV-2) antibodies among healthcare workers with differing levels of coronavirus disease 2019 (COVID-19) patient exposure. Infect Control Hosp Epidemiol. 2020;41:1441-2. https:/ / doi.org/10.1017/ice.2020.390

27. Lentz RJ, Colt H, Chen H, Cordovilla R, Popevic S, Tahura S, et al. Assessing coronavirus disease 2019 (COVID-19) 
transmission to healthcare personnel: the global ACT-HCP case-control study. Infect Control Hosp Epidemiol. 2021;42:381-7. https://doi.org/10.1017/ ice.2020.455

28. Lai X, Wang X, Yang Q, Xu X, Tang Y, Liu C, et al. Will healthcare workers improve infection prevention and control behaviors as COVID-19 risk emerges and increases, in China? Antimicrob Resist Infect Control. 2020;9:83. https:/ / doi.org/10.1186/s13756-020-00746-1

29. O'Neil CA, Li J, Leavey A, Wang Y, Hink M, Wallace M, et al.; Centers for Disease Control and Prevention Epicenters Program. Characterization of aerosols generated during patient care activities. Clin Infect Dis. 2017;65:1335-41. https://doi.org/10.1093/cid/cix535
30. Brown J, Gregson FKA, Shrimpton A, Cook TM, Bzdek BR, Reid JP, et al. A quantitative evaluation of aerosol generation during tracheal intubation and extubation. Anaesthesia. 2021;76:174-81. https://doi.org/10.1111/anae.15292

31. Schmitz D, Vos M, Stolmeijer R, Lameijer H, Schönberger T, Gaakeer MI, et al. Association between personal protective equipment and SARS-CoV-2 infection risk in emergency department healthcare workers. Eur J Emerg Med. 2021;28:2029. https://doi.org/10.1097/MEJ.0000000000000766

Address for correspondence: Nora Chea, Centers for Disease Control and Prevention, 1600 Clifton Rd NE, Mailstop H16-2, Atlanta, GA 30329-4027, USA; email: xdc7@cdc.gov

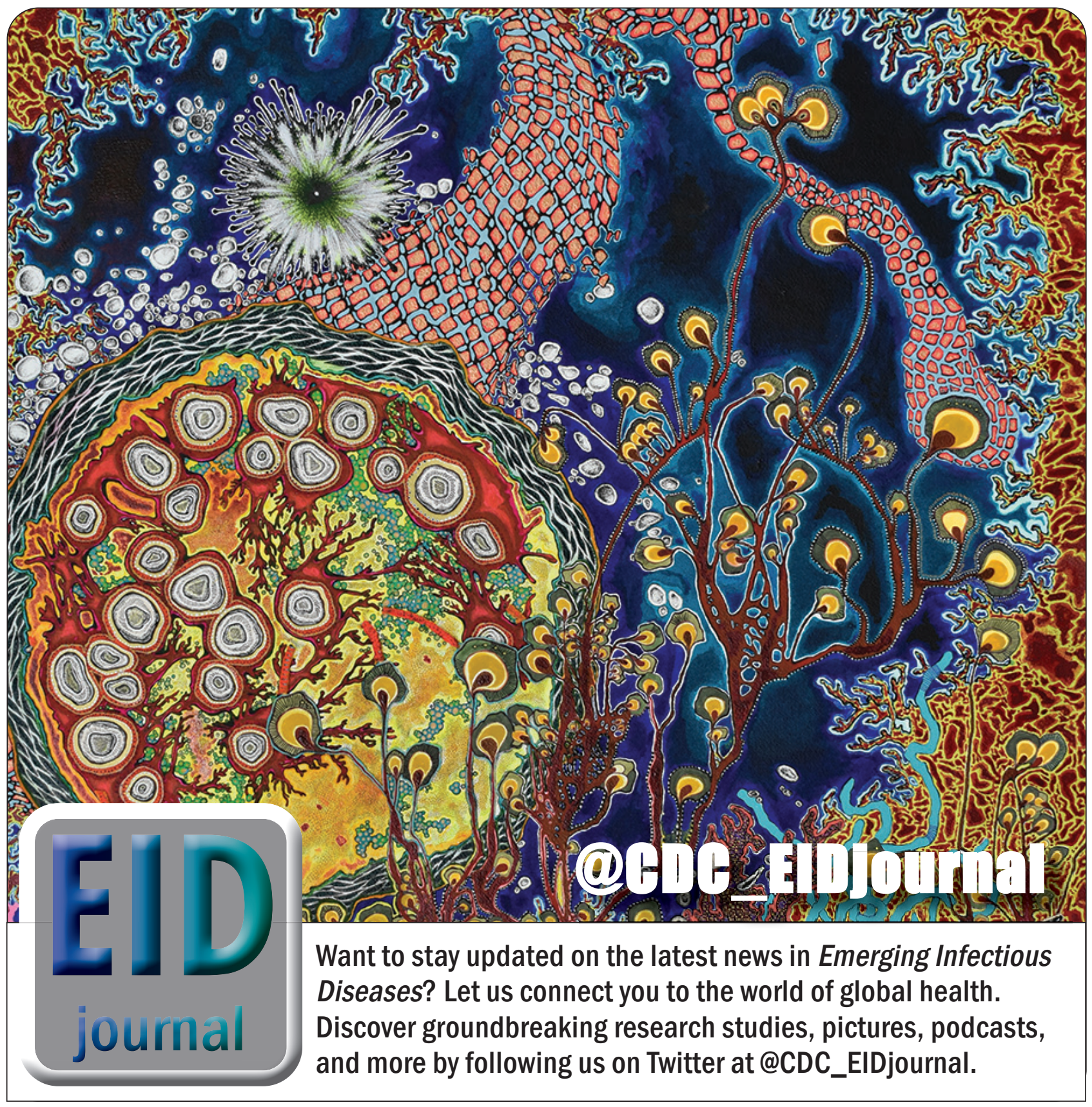

